\title{
The bivalency effect represents an interference-triggered adjustment of cognitive control: An ERP study
}

\author{
Alodie Rey-Mermet • Thomas Koenig • Beat Meier
}

Published online: 13 April 2013

(C) Psychonomic Society, Inc. 2013

\begin{abstract}
When bivalent stimuli (i.e., stimuli with relevant features for two different tasks) occur occasionally among univalent stimuli, performance is slowed on subsequent univalent stimuli even if they have no overlapping stimulus features. This finding has been labeled the bivalency effect. It indexes an adjustment of cognitive control, but the underlying mechanism is not well understood yet. The purpose of the present study was to shed light on this question, using event-related potentials. We used a paradigm requiring predictable alternations between three tasks, with bivalent stimuli occasionally occurring on one task. The results revealed that the bivalency effect elicited a sustained parietal positivity and a frontal negativity, a neural signature that is typical for control processes implemented to resolve interference. We suggest that the bivalency effect reflects interference, which may be caused by episodic context binding.
\end{abstract}

Keywords Bivalent stimuli · Task switching · Conflict

Cognitive control is the ability to adjust performance flexibly according to momentary requirements. It enables us to select goal-relevant features while inhibiting irrelevant ones. When a conflict is encountered, adjustment of cognitive control does not only affect performance for processing the current conflict-loaded event. It may also affect the processing of subsequent events (e.g., Botvinick, Braver, Barch, Carter, \& Cohen, 2001; Egner, 2007, 2008). For instance, cognitive control is not only adjusted for trials with

A. Rey-Mermet $\cdot$ B. Meier $(\square)$

Department of Psychology and Center for Cognition, Learning, and Memory, University of Bern, Muesmattstr. 45,

3000 Bern 9, Switzerland

e-mail: beat.meier@psy.unibe.ch

T. Koenig

Department of Psychiatric Neurophysiology, University Hospital of Psychiatry, and Center for Cognition, Learning, and Memory, University of Bern, Bern, Switzerland bivalent stimuli (i.e., stimuli with relevant features for two different tasks; Jersild, 1927; Meiran, 2008). It is also adjusted for subsequent trials with univalent stimuli (i.e., stimuli with relevant features for one task) even if they have no overlapping features with the bivalent stimuli (Meier, Rey-Mermet, Woodward, Müri, \& Gutbrod, 2013; Meier, Woodward, Rey-Mermet, \& Graf, 2009; Rey-Mermet \& Meier, 2012a, 2012b; Woodward, Meier, Tipper, \& Graf, 2003; Woodward, Metzak, Meier, \& Holroyd, 2008; see Meier \& Rey-Mermet, 2012a, for a review). It is, however, unclear how the latter adjustment of cognitive controllabeled the bivalency effect -is implemented. The purpose of the present study was to shed light on this question.

In the previous studies investigating the bivalency effect, participants were asked to repeatedly switch between three binary decision tasks (Grundy et al., 2011; Meier et al., 2009; Rey-Mermet \& Meier, 2012a, 2012b; Woodward et al., 2003; Woodward et al., 2008). For example, participants were asked to perform a task triplet consisting of a color decision (red vs. blue), a parity decision (odd vs. even), and a case decision (uppercase vs. lowercase; see Fig. 1 for an example). The tasks were presented in the same order and typically involved univalent stimuli (i.e., red or blue symbols for the color decision, black numerals for the parity decision, and black letters for the case decision). However, for some case decisions, the letters were displayed in either red or blue print color, thus turning them into bivalent stimuli. The results revealed the bivalency effect-that is, a performance slowing for all univalent trials following bivalent stimuli, including those with stimuli that shared no relevant stimulus features with the bivalent stimuli (i.e., the parity decision trials; see Woodward et al., 2003). This finding was extended to different types of tasks (size, vowel/consonant), to a different type of bivalent stimuli (large/small letters), and to a different modality (auditory; Meier et al., 2009). Moreover, the bivalency effect is not dependent on the conflict created by overlapping responses, because it also occurs on univalent trials that share no 
response features with the bivalent stimuli (Rey-Mermet \& Meier, 2012a).

So far, only two studies have investigated the neural correlates of the bivalency effect. Using functional magnetic resonance imagery (fMRI), Woodward et al. (2008) showed that the bivalency effect was associated with activation in the dorsal anterior cingulate cortex (dACC), a brain area typically involved in adjustment of cognitive control (see Botvinick et al., 2001; Botvinick, Cohen, \& Carter, 2004). Using event-related potentials (ERPs), Grundy et al. (2011) investigated the time course of ERP activity that corresponds to the anterior cingulate cortex activity reported in the fMRI study. They showed that the bivalency effect was associated with three different ERP deflections at frontal electrodes: a larger negative deflection that peaked approximately $100 \mathrm{~ms}$ after stimulus onset and two smaller negative deflections that peaked approximately 375 and $500 \mathrm{~ms}$ after stimulus onset. Source localizations showed activity in the temporal junction for the first ERP deflection and in the AACC for the last two ERP deflections, thus complementing the fMRI results.

However, these results did not consider the specific trajectory of the bivalency effect. Although Meier et al. (2009) showed that the bivalency effect endured at least across the four task triplets following bivalent stimuli, the results also revealed a sharp decline from the first to the second task triplet following a bivalent stimulus. After that, the bivalency effect remained stable (see also Meier \& Rey-Mermet, 2012a). This suggests that the bivalency effect involves two different components: one that is short-lived, most likely related to an orienting response caused by the infrequence of bivalent stimuli (cf. Notebaert et al., 2009; Notebaert \& Verguts, 2011; Nùñez Castellar, Kühn, Fias, \& Notebaert, 2010) and one that is long-lived and reflects a subsequent adjustment of cognitive control (i.e., the bivalency effect proper).

The purpose of the present study was to use ERPs to investigate the processes underlying the bivalency effect proper. To this end, we focused on the bivalency effect unconfounded by a potential orienting response. The general method involved three blocks with regular switches between a color decision on symbols, a parity decision on numerals, and a case decision on letters. In the first and third blocks (the pure blocks), all stimuli were univalent. In the second block (the mixed block), some letters for the case decisions appeared in red or blue color, which turned them into bivalent stimuli. As compared with the ERP study by Grundy et al. (2011), we implemented two changes to keep the orienting response as low as possible. First, we informed participants about the presence of bivalent stimuli, and we specifically instructed them to ignore color information and to focus on making case decisions. Second, we excluded the first task triplet immediately following bivalent stimuli from the analyses.

Since the bivalency effect reflects an adjustment of cognitive control triggered by bivalent stimuli, the slowing on subsequent univalent stimuli is assumed to be the expression of some kind of interference (Grundy et al., 2011; Meier \& Rey-Mermet, 2012a; Rey-Mermet \& Meier, 2012a, 2012b; Woodward et al., 2008). In ERP research, three components that represent a signature of interference are typically discussed: the N2, the $\mathrm{N} 450$, and the sustained potential (SP). The N2 component represents a negative fronto-central deflection that emerges between 250 and $350 \mathrm{~ms}$ after stimulus onset (Clayson \& Larson, 2011; Gehring, Gratton, Coles, \& Donchin, 1992; Kopp, Rist, \& Mattler, 1996; Spapé, Band, \& Hommel, 2011). The N450 is also a frontocentral negative-going deflection that peaks approximately $450 \mathrm{~ms}$ after stimulus onset (Larson, Kaufman, \& Perlstein, 2009; Liotti, Woldroff, Perez, \& Mayberg, 2000; Markela-Lerenc et al., 2004; West, 2003; West, Bowry, \& McConville, 2004; West, Jakubek, Wymbs, Perry, \& Moore, 2005). The SP is a more tonic and sustained potential and reflects a frontal negativity and a parietal positivity approximately $600 \mathrm{~ms}$ after stimulus onset (Larson et al., 2009; Liotti et al., 2000; West, 2003; West et al., 2005).

Functionally, the N2 is related to response interference (e.g., Van Veen \& Carter, 2002) and the N450 is related to stimulus-specific interference (e.g., Brass, Ullsperger, Knoesche, von Cramon, \& Phillips, 2005), while the SP has been related specifically to control processes implemented to resolve interference (Larson et al., 2009; Wylie, Javitt, \& Foxe, 2003). Previous research has shown that response interference is not sufficient to explain the bivalency effect (Rey-Mermet \& Meier, 2012a). Moreover, the bivalency effect is not restricted to the bivalent stimulus (or to univalent stimuli with overlapping stimulus features; e.g., Woodward et al., 2003). Rather, the bivalency effect is related to control processes that are implemented to resolve interference on subsequent task triplets. Thus, we expected most likely to find the SP component.

\section{Method}

\section{Participants}

The participants were 20 right-handed students (16 women; mean age $=22.1$ years, $S D=3.3$ ) from the University of Bern. They were recruited from the departmental participant pool and received course credits for participation. All of 
them had normal or corrected-to-normal visual acuity and reported no evidence of neurological compromise. The study was approved by the local ethics committee. Informed written consent was obtained from each participant. ${ }^{1}$

\section{Materials}

For the color decision, the stimuli were the symbols \%, $\#, *$, and $\S$, each displayed in either blue or red. For the parity decision, the stimuli were the numerals 1 through 8, each displayed in black. For the case decision, the stimuli were the upper- or lowercase consonants $d, f, r$, and $t$, each displayed in black (cf. Meier et al., 2009). We created a set of eight bivalent stimuli by presenting the same four consonants $(d, f, r, t)$ in either blue or red and in either upper- or lowercase. All stimuli were displayed at the center of the computer screen in 60point Times New Roman font.

\section{Procedure}

Participants were tested individually. They were informed that the experiment involved three different tasks: color decisions about symbols, parity decisions about numerals, and case decisions about letters. They were instructed to press one of two computer keys ( $b$ and $n$ ) with their index and middle fingers, respectively, for each of the three tasks. Half of the participants were required to use the right hand, the other half the left hand, in order to negate activations solely attributable to the act of responding. The mapping information, printed on paper, was displayed below the computer screen throughout the experiment. Participants were further informed that, for some of the case decisions, the letters would be presented in color. They were specifically instructed to ignore color information and to focus on making case decisions.

\footnotetext{
${ }^{1}$ Originally, we had designed the study to address an additional question-namely, how retroactive and proactive control (cf. Braver, 2012; Braver, Gray, \& Burgess, 2007) differ in terms of the recruited neuronal modulations. In a first condition (the retroactive condition), participants were asked to perform the case decisions and not the color decision when encountering bivalent stimuli. In another condition (the proactive control condition; see Meier \& Rey-Mermet, 2012b), they were instructed to press the $h$ - key when encountering the bivalent stimuli. We counterbalanced the order of these conditions across two sessions that were separated by 1 week. Half of the participants performed the retroactive condition in the first session and the proactive condition in the second session. The other half of the participants performed the proactive condition in the first session and the retroactive condition in the second session. It turned out that counterbalancing worked properly for the retroactive condition (i.e., the pattern of results was similar across conditions), but not for the proactive condition. Therefore, we focus exclusively on the results of the retroactive condition (i.e., the bivalency effect).
}

After these instructions, a block of 40 task triplets was presented for practice. Each task triplet required making a color decision, a parity decision, and a case decision, always in the same order, as illustrated in Fig. 1. The stimulus for each task was randomly determined and displayed for $1,500 \mathrm{~ms}$. Then the screen blanked for $500 \mathrm{~ms}$, and the next stimulus appeared. After the practice block and a brief break, each participant completed three experimental blocks without any break between blocks. The first block included 42 task triplets, with the first 2 task triplets serving as "warm-up" sequences, which were discarded from the analyses. The second and third blocks had only 40 task triplets each.

For the first and third blocks (the pure blocks), only univalent stimuli were presented. For the second block (the mixed block), stimuli were univalent except on $20 \%$ of the case decisions in which bivalent stimuli (i.e., red or blue letters) appeared. Bivalent stimuli were determined randomly and without replacement. Task triplets with bivalent stimuli were evenly interspersed among the 40 task triplets of the block, occurring in every fifth task tripletspecifically, in the 3rd, 8th, 13th, 18th, 23th, 28th, 33th, and 38th triplets.

\section{EEG recording and processing}

Participants were seated in an electrically shielded, soundproofed, and air-conditioned recording room in front of a computer display (distance $60 \mathrm{~cm}$ ). The EEG was digitized (500 Hz, $0.015-250 \mathrm{~Hz}$ band-pass) and stored from 62 electrodes located according to an extended version of the International 10-20 System using Brainproducts EEG system. Interelectrode impedances were kept below $5 \mathrm{k} \Omega$. All electrodes were recorded against $\mathrm{Fz}$ and were grounded to

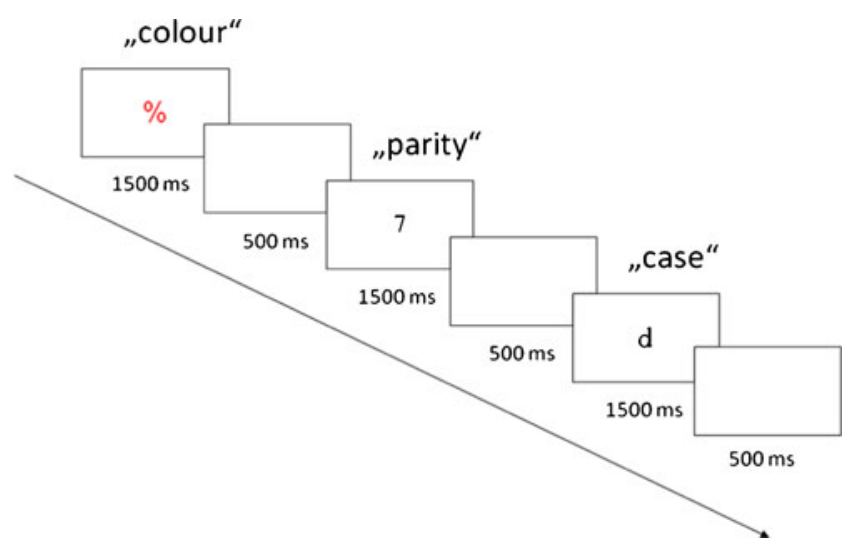

Fig. 1 Example of one univalent task triplet. Participants carried out a color decision (red vs. blue) on symbols, a parity decision (odd vs. even) on numerals, and a case decision (upper- vs. lowercase) on letters. On a bivalent task triplet (not pictured here), the letters were presented in red or blue print color 
AFz. Eye movements were monitored with two additional electrooculogram channels.

First, for offline data analysis, an independent component analysis (ICA) based eye movement correction was applied (Delorme, Sejnowski, \& Makeig, 2007). Across participants, between two and four ICA components were related to eye movements and were removed. Further artifacts were identified by visual inspection. The data were filtered offline with a band-pass filter from 0.5 to $20 \mathrm{~Hz}$ and recomputed against average reference. Since the reaction times (RTs) were in the 600- to 800 -ms range, we report only artifactfree ERP effects occurring from $200 \mathrm{~ms}$ before stimulus presentation to $800 \mathrm{~ms}$ after stimulus presentation for correct responses.

\section{Behavioral and ERP data analysis}

For each participant, the accuracy rates, the median RTs, and the ERPs for correct responses were computed for each task and each block. To account for general training effects, we averaged the data from the pure blocks 1 and 3 for each task. To eliminate the orienting response, the task triplets containing bivalent stimuli and those immediately following bivalent stimuli were excluded. The corresponding task triplets in the pure blocks 1 and 3 were also excluded. Additionally, for the behavioral data, error rates, and median RTs for bivalent case decisions were computed.

\section{Behavioral and ERP statistical analysis}

For the behavioral statistical analysis, we first conducted a $t$ test comparing bivalent and univalent case decisions from the mixed block in order to test the impact of bivalent stimuli, as compared with univalent stimuli (cf. Jersild, 1927; Meiran, 2008). ${ }^{2}$ To investigate the bivalency effect, we carried out a two-way within-subjects analysis of variance (ANOVA) on univalent stimuli, with the factors block (pure, mixed) and task (color, parity, case). An alpha level of .05 was used for all statistical tests. Greenhouse-Geisser corrections are reported where appropriate, and effect sizes are expressed as partial $\eta^{2}$ values.

For the ERP statistical analysis, we used the software RAGU (Randomization Graphical User Interface; Koenig, Kottlow, Stein, \& Melie-Garcia, 2011; Koenig \& MelieGarcia, 2009, 2010). To investigate the bivalency effect, we first performed a topographic ANOVA (TANOVA), normalized across electrodes, as a global test for topographic differences (Strik, Fallgatter, Brandeis, \& Pascual-Marqui, 1998; Wirth et al., 2008). This TANOVA involved a $2 \times 3$

\footnotetext{
$\overline{2}$ By design, it was not possible to compare ERPs between univalent and bivalent trials because there were only eight bivalent trials.
}

design, with the within-subjects factors block (pure, mixed) and task (color, parity, case). Then we conducted a global duration test in order to indicate the maximum duration of consecutive significant time points that can be expected above the chance level .05 (Koenig et al., 2011; Koenig \& Melie-Garcia, 2009, 2010). TANOVA differences whose consecutive time points were significant were further explored using paired topographic maps (t-maps), which inform about the scalp distribution of the signal-to-noise ratio of an effect.

\section{Results}

Behavioral results

\section{Performance on bivalent stimuli}

In the mixed block, participants were significantly slower on bivalent stimuli than on the corresponding univalent stimuli (i.e., on the univalent case decisions from the mixed block), $t(19)=4.97, p<.001\left(M_{\text {bivalent }}=814 \mathrm{~ms}, S E=46 ; M_{\text {univalent }}=\right.$ $629 \mathrm{~ms}, S E=26)$. Moreover, they were significantly less accurate on bivalent stimuli than on the corresponding univalent stimuli, $t(19)=-2.71, p<.05\left(M_{\text {bivalent }}=.91, S E=.03\right.$; $\left.M_{\text {univalent }}=.99, S E=.005\right)$.

\section{Performance on univalent stimuli}

Results are summarized in Table 1. The ANOVA on the RTs of univalent stimuli revealed a significant main effect of block, $F(1,19)=18.18, p<.001, \eta^{2}=.49$, and of task, $F(2$, $38)=14.20, p<.001, \eta^{2}=.43$. The interaction between these factors was not significant, $F(2,38)=1.89, p=.16, \eta^{2}=.09$. Thus, performance was significantly slowed $(M=49 \mathrm{~ms}$, $S E=12$ ) for all three tasks in the mixed block, as compared with the pure block. This confirms the presence of the bivalency effect.

The ANOVA on the accuracy of the univalent stimuli showed a significant main effect of task, $F(2,38)=13.55, p$

Table 1 Mean reaction times (in milliseconds) for the univalent task triplets in the pure block and in the mixed block (with standard errors in parentheses)

\begin{tabular}{llll}
\hline Task & Pure block & Mixed block & Difference \\
\hline Color & $662(24)$ & $735(37)$ & $73(20)$ \\
Parity & $675(30)$ & $714(34)$ & $39(14)$ \\
Case & $593(20)$ & $629(26)$ & $36(15)$ \\
\hline
\end{tabular}

Note. Means are based on individual median reaction times of correct responses out of 21 decisions. The task triplets immediately following bivalent stimuli in the mixed block and the corresponding task triplets in the pure block were excluded. 
$<.001, \eta^{2}=.42$. Thus, participants were more accurate on the case decisions $(M=.99, S E=.004)$ than on the color and parity decisions $(M=.94, S E=.01$, and $M=.95, S E=.01$, respectively). No other main effect or interaction was significant, $F_{\mathrm{S}}<1, p_{\mathrm{S}}>.05, \eta^{2}<.02$. These results indicate that no speed-accuracy trade-off compromised the critical RT effects.

\section{ERP results}

\section{Performance on univalent stimuli}

The analysis of the bivalency effect was based on an average of 35.5, 35.6, and 36.2 (range $=27-41$ ) valid univalent trials for the color, parity, and case decisions per participant from the pure block, and 16.8, 18.1, and 18.7 (range=13-21) valid univalent trials for the color, parity, and case decisions per participant from the mixed block. The TANOVA and the global duration test revealed a significant main effect of block in the time window 606-774 ms $(p<.05)$. Furthermore, the main effect of task was also significant in two time windows: $126-570$ and $670-778 \mathrm{~ms}(p s<.05)$. No time window was significant for the interaction, $p>.05$. Thus, a significant difference between the univalent task triplets from the mixed block and those from the pure block was found in a time window about $650 \mathrm{~ms}$ after stimulus onset. Figure 2 shows the grand-mean traces of the univalent task triplets from the mixed block and those from the pure block at selected electrodes and the t-map of differences between the two blocks for this time window. The figure shows that the largest positive differences occurred at parietal electrodes (largest $t$-value at electrode P8, $t$-value $=2.53$ ) and the most negative differences occurred at frontal electrodes (smallest $t$-value at electrode Fpz, $t$-value $=-2.41$ ). Thus, the bivalency effect was associated with a frontal negativity and a parietal positivity about $650 \mathrm{~ms}$ after stimulus onset.

\section{Discussion}

The purpose of the present study was to use ERPs in order to examine the processes underlying the bivalency effect proper. The first task triplet following bivalent stimuli was excluded from the analyses in order to eliminate the potential influence of an orienting response resulting from the infrequent bivalent stimuli and to focus on the long-lasting component of the bivalency effect.

The behavioral results showed that performance was slowed on univalent stimuli after bivalent stimuli were presented, even on those stimuli that had no overlapping stimulus features with the bivalent stimuli. This replicates the long-lasting nature of the bivalency effect (Meier et al., 2009). The ERP results revealed that the bivalency effect was associated with a frontal negativity and a parietal positivity approximately $650 \mathrm{~ms}$ after stimulus onset. This neural signature reflects the SP component usually found when interference is increased (Liotti et al., 2000; West, 2003; West et al., 2005). More specifically, this component has been related to control processes implemented to resolve interference (Larson et al., 2009; Wylie et al., 2003). Therefore, the present results suggest that when the orienting response is eliminated, the bivalency effect reflects control processes implemented to resolve interference.

According to the current theories of cognitive control, interference typically stems from divergent stimulus or response features (cf. Allport, Styles, \& Hsieh, 1994; Botvinick et al., 2001; Egner, 2007, 2008; Hommel, 2004; Rogers \& Monsell, 1995; Waszak, Hommel, \& Allport, 2003; see Vandierendonck, Liefooghe, \& Verbruggen, 2010). Thus, after a bivalent stimulus is encountered, bivalent stimulus features will be activated on the univalent trials that share a stimulus or response feature with the bivalent stimulus. These bivalent stimulus features will interfere with trial processing, because they are irrelevant for task execution. Thus, they will be inhibited (Allport et al., 1994; Allport \& Wylie, 1999, 2000; Wylie \& Allport, 2000), or they will require an additional task decision process in order to select the relevant task (Braverman \& Meiran, 2010; Fagot, 1994; Meiran, Kessler, \& Adi-Japha, 2008; Rogers \& Monsell, 1995). In both cases, performance will be slowed, but only for the univalent trials sharing relevant features with the bivalent stimuli. However, the bivalency effect is also found on the univalent trials sharing no relevant stimulus or response features with the bivalent stimuli (e.g., Meier et al., 2009; Rey-Mermet \& Meier, 2012a; Woodward et al., 2003). Therefore, the interference as proposed in the current cognitive control accounts cannot fully explain the bivalency effect.

Another possibility would be that participants are monitoring for bivalent stimuli and that this monitoring interferes with the processing of univalent trials (e.g., Guynn, 2003; Smith, 2003). However, in a recent study, we found that monitoring for bivalent stimuli did not result in the bivalency effect. In this study, we asked participants to respond with a different key when encountering bivalent stimuli (Meier \& Rey-Mermet, 2012b). The results showed a performance slowing for the first task triplet that immediately followed the bivalent stimuli, probably reflecting an orienting response (cf. Notebaert et al., 2009; Notebaert \& Verguts, 2011; Nùñez Castellar et al., 2010). In addition, on subsequent task triplets, a performance slowing was found, but only on those univalent stimuli that shared relevant features with bivalent stimuli (i.e., the color and case decisions). Therefore, interference due to monitoring does not result in the same pattern of slowing as the bivalency effect. 

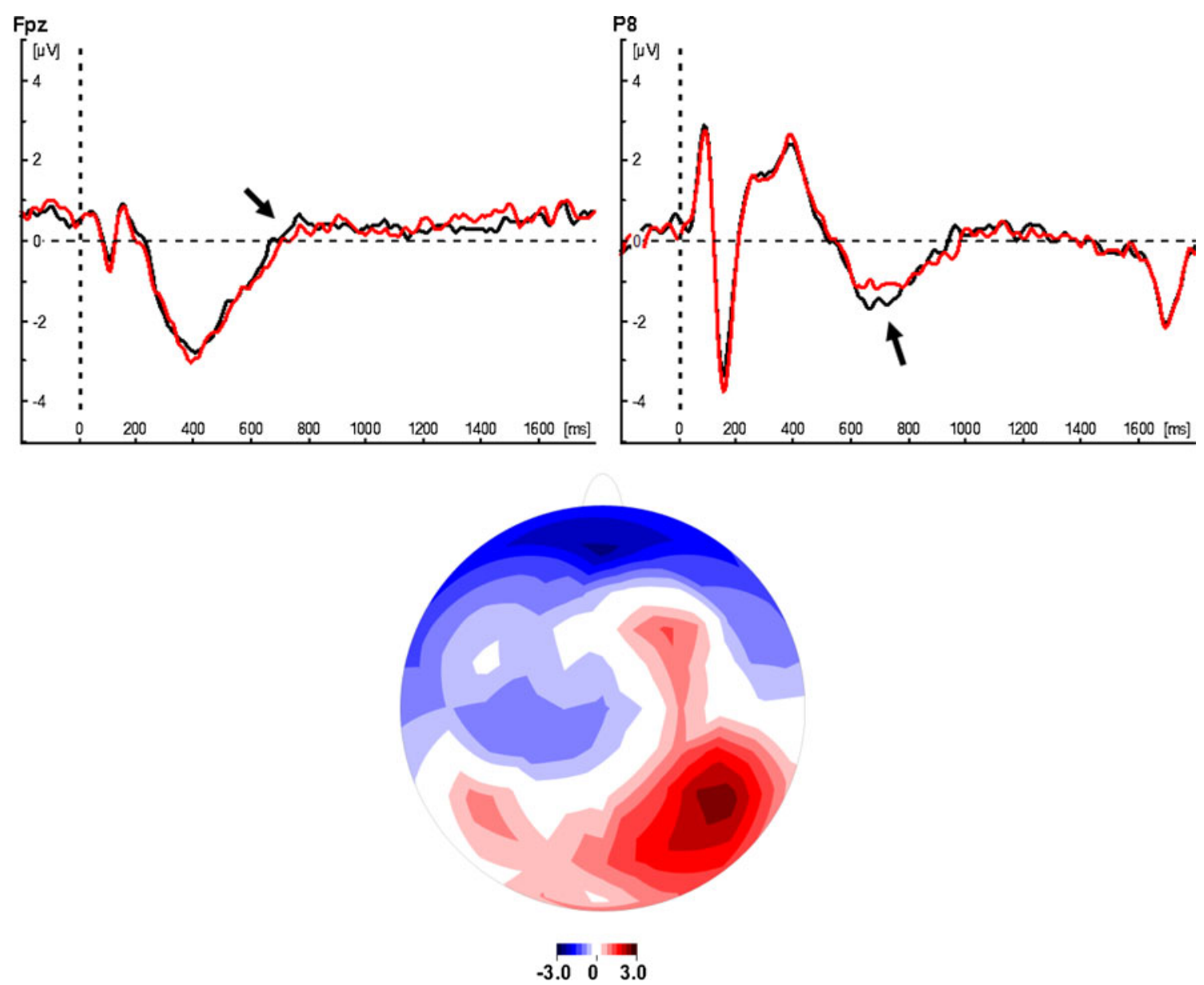

Fig. 2 Neural signature of the bivalency effect proper. Upper panels: Grand-mean traces of the univalent task triplets for the pure block (black lines) and the mixed block (red lines) at selected electrodes (Fpz and P8). Lower panels: Topographic map (t-map) of the bivalency effect proper in the significant time window $606-774 \mathrm{~ms}$ detected by the TANOVA and the global duration test. Red areas represent an increase in activity; blue areas represent a decrease in activity
Consequently, the interference underlying the bivalency effect must stem from a different source, beyond stimulus, response, or task features. For example, it might result from the reactivation of the context created by occasionally encountering bivalent stimuli. We have suggested that a stimulus and a task are bound to the context in which they occur, resulting in episodic context binding that is updated again and again (Meier \& Rey-Mermet, 2012a; Meier et al., 2009; Rey-Mermet \& Meier, 2012a). In the particular paradigm used to assess the bivalency effect, from the perspective of a participant, the context consists of the whole task triplet and typically involves univalent stimuli. Stimuli and tasks are bound to this context, which is reactivated on a subsequent task triplet. The occurrence of a bivalent stimulus creates a more demanding context. Thus, on subsequent task triplets, the representation of the - now conflict-loaded - context is reactivated and interferes with processing the univalent trials. This slows down performance and results in the bivalency effect. Thus, according to the episodic context binding account, the bivalency effect reflects interference caused by the reactivation of the more demanding context created by bivalent stimuli. Although this explanation is still somewhat speculative, it is in line with the results of the present study. Moreover, it is also consistent with a recent study in which we tested the bivalency effect in amnesic patients. We hypothesized that due to their severe problems in memory binding, amnesic patients would fail to show a normal bivalency effect. The results were in line with this prediction (Meier et al., 2013). Nevertheless, further evaluation of the episodic context account is necessary. For example, it would be interesting to test whether the sequential presentation of the tasks is necessary for episodic context binding to occur, or whether the bivalency effect would end quickly if one of the tasks in a triplet were also changed, since that would change the context. Moreover, it would also be interesting to follow up the present study using fMRI in order to further investigate the neural correlates of episodic context binding. 
The present results extend the findings on cognitive control effects following a conflict, such as the conflict adaptation effects in the Stroop, Simon, and flanker tasks. ${ }^{3}$ Similar to conflict adaptation in the Stroop task, the bivalency effect is also associated with the SP component in ERPs (Larson et al., 2009). Per definition, the bivalency effect involves a task conflict triggered by bivalent stimuli. In the Stroop task, incongruent stimuli also trigger a task conflict (Seinhauser \& Hübner, 2009). Thus, on both occasions, the SP component seems to reflect control processes implemented to resolve interference due to a task conflict. In contrast, conflict adaptation in both the Simon and flanker tasks is typically associated with the N2 component, and this component is interpreted as interference due to a response conflict (Clayson \& Larson, 2012; Spapé et al., 2011). Importantly, the N2 component was not present for the bivalency effect, which is consistent with previous findings that demonstrated that the bivalency effect occurs whether or not a response conflict is present (Rey-Mermet \& Meier, 2012a). Thus, response interference is not critical for the occurrence of the bivalency effect. However, in order to compare the bivalency effect directly with the conflict adaptation effect, further research is required in which both paradigms are closely matched.

As in the previous studies, the present study focused on retroactive cognitive control (cf. Braver, 2012; Braver et al., 2007; but see Meier \& Rey-Mermet, 2012b). An interesting avenue for future research is to determine the commonalities and differences between retroactive and proactive control, a control mode in which goal relevant information is actively maintained in a sustained manner before a cognitively demanding event occurs.

\footnotetext{
${ }^{3}$ In these tasks, incongruent stimuli are intermixed with congruent stimuli. Specifically, in the Stroop task, participants are usually asked to indicate the color of a color word. For some stimuli, the color and the word are congruent (e.g., the word "red" written in red); for some other stimuli, the color and the word are incongruent (e.g., the word "red" written in blue). In the Simon task, stimuli are presented either to the left or to the right of a central fixation, and participants are asked to make a simple decision (e.g., a color decision) by pressing keys with their left or right hand. Congruent Simon stimuli are, for example, stimuli presented to the left requiring a left response; incongruent Simon stimuli are stimuli presented to the left but requiring a right response. In the flanker task, stimuli consist of strings of letters (e.g., $\mathrm{HHH}$ or SHS), and participants are asked to indicate the identity of the central letter. Incongruent flanker stimuli are letter strings in which the central letter is different from the flanking letters (e.g., SHS). In all three tasks, performance is slower on incongruent trials than on congruent trials, resulting in a congruency effect. Moreover, this congruency effect is reduced after incongruent stimuli, resulting in the socalled conflict adaptation effect. The conflict adaption effect has been generally interpreted as an adjustment of cognitive control following the conflict induced by incongruent stimuli (Botvinick et al., 2001; Egner, 2007; Ullsperger, Bylsma, \& Botvinick, 2005).
}

In sum, the findings of the present study provide evidence that the bivalency effect is associated with a neural signature related specifically to control processes implemented to resolve interference. In line with previous findings, this suggests that the bivalency effect reflects interference caused by the reactivation of the more demanding context created by bivalent stimuli.

Author Note This work was supported by a grant from the JanggenPöhn Foundation to A. Rey-Mermet, by a grant from the Swiss National Science Foundation (Grant 130104) to B. Meier and by the Center for Cognition Learning and Memory, University of Bern. We thank Julia Kummer and Tullia Padovani for assistance in conducting the experiment and Stefan Walter for helpful comments on an earlier version.

\section{References}

Allport, A., Styles, E. A., \& Hsieh, S. (1994). Shifting intentional set: Exploring the dynamic control of tasks. In C. Umilta \& M. Moscovitch (Eds.), Attention and performance XV: Conscious and nonconscious information processing (pp. 421-452). Cambridge, MA: MIT Press.

Allport, A., \& Wylie, G. (1999). Task-switching: Positive and negative priming of task-set. In G. W. Humphreys, J. Duncan, \& A. M. Treisman (Eds.), Attention, space and action: Studies in cognitive neuroscience (pp. 273-296). Oxford, England: Oxford University Press.

Allport, A., \& Wylie, G. (2000). Task-switching, stimulus-response bindings, and negative priming. In S. Monsell \& J. S. Driver (Eds.), Control of cognitive processes: Attention and performance XVIII (pp. 35-70). Cambridge, MA: MIT Press.

Botvinick, M. M., Braver, T. S., Barch, D. M., Carter, C. S., \& Cohen, J. D. (2001). Conflict monitoring and cognitive control. Psychological Review, 108, 624-652. doi:10.1037//0033295X.108.3.624

Botvinick, M. M., Cohen, J. D., \& Carter, C. S. (2004). Conflict monitoring and anterior cingulate cortex: An update. Trends in Cognitive Sciences, 8, 539-546. doi:10.1016/j.tics.2004.10.003

Brass, M., Ullsperger, M., Knoesche, T. R., von Cramon, D. Y., \& Phillips, N. A. (2005). Who comes first? The role of the prefrontal and parietal cortex in cognitive control. Journal of Cognitive Neuroscience, 17, 1367-1375. doi:10.1162/0898929054985400

Braver, T. S. (2012). The variable nature of cognitive control: A dual mechanisms framework. Trends in Cognitive Sciences, 16, 106113. doi:10.1016/j.tics.2011.12.010

Braver, T. S., Gray, J. R., \& Burgess, G. C. (2007). Explaining the many varieties of working memory variation: Dual mechanisms of cognitive control. In A. R. A. Conway, C. Jarrold, M. J. Kane, A. Miyake, \& J. N. Towse (Eds.), Variation in Working Memory (pp. 76-106). Oxford, England: Oxford University Press.

Braverman, A., \& Meiran, N. (2010). Task conflict in task switching. Psychological Research, 74, 568-578. doi:10.1007/s00426-0100279-2

Clayson, P. E., \& Larson, M. J. (2011). Conflict adaptation and sequential trial effects: Support for the conflict monitoring theory. Neuropsychologia, 49, 1953-1961. doi:10.1016/ j.neuropsychologia.2011.03.023

Clayson, P. E., \& Larson, M. J. (2012). Cognitive performance and electrophysiological indices of cognitive control: A validation study of conflict adaptation. Psychophysiology, 49, 627-637. doi:10.1111/j.1469-8986.2011.01345.x 
Delorme, A., Sejnowski, T., \& Makeig, S. (2007). Enhanced detection of artefacts in EEG data using higher-order statistics and independent component analysis. NeuroImage, 34, 1443-1449. doi:10.1016/ j.neuroimage.2006.11.004

Egner, T. (2007). Congruency sequence effects and cognitive control. Cognitive, Affective, \& Behavioral Neuroscience, 7, 380-390. doi:10.3758/CABN.7.4.380

Egner, T. (2008). Multiple conflict-driven control mechanisms in the human brain. Trends in Cognitive Neuroscience, 12, 374-380. doi:10.1016/j.tics.2008.07.001

Fagot, C. (1994). Chronometric investigations of task switching (Unpublished doctoral dissertation). University of California, San Diego.

Gehring, W. J., Gratton, G., Coles, M. G. H., \& Donchin, E. (1992). Probability effects of stimulus evaluation and response processes. Journal of Experimental Psychology. Human Perception and Performance, 18, 198-216. doi:10.1037//0096-1523.18.1.198

Grundy, J. G., Benarroch, M. F. F., Woodward, T. S., Metzak, P. D., Whitman, J. C., \& Shedden, J. M. (2011). The bivalency effect in task switching: Event-related potentials. Human Brain Mapping. doi: $10.1002 / \mathrm{hbm} .21488$

Guynn, M. J. (2003). A two-process model of strategic monitoring in event-based prospective memory: Activation/retrieval mode and checking. International Journal of Psychology, 38, 245-256. doi:10.1080/00207590244000205

Hommel, B. (2004). Event files: Feature binding in and across perception and action. Trends in Cognitive Sciences, 8, 494-500. doi:10.1016/ j.tics.2004.08.007

Jersild, A. T. (1927). Mental set and shift. Archives of Psychology, 89, 5-82.

Koenig, T., Kottlow, M., Stein, M., \& Melie-Garcia, L. (2011). Ragu: A free tool for the analysis of EEG and MEG event-related scalp field data using global randomization statistics. Computational Intelligence and Neuroscience, 2011, 1-14. doi:10.1155/2011/ 938925

Koenig, T., \& Melie-Garcia, L. (2009). Statistical analysis of multichannel scalp field data. In C. M. Michel, T. Koenig, D. Brandeis, L. R. R. Gianotti, \& J. Wackermann (Eds.), Electrical Neuroimaging (pp. 169-190). New York: Cambridge University Press.

Koenig, T., \& Melie-Garcia, L. (2010). A method to determine the presence of averaged event-related fields using randomization tests. Brain Topography, 23, 233-242. doi:10.1007/s10548-0100142-1

Kopp, B., Rist, F., \& Mattler, U. (1996). N200 in the flanker task as a neurobehavioral tool for investigating executive control. Psychophysiology, 33, 282-294. doi:10.1111/j.1469-8986.1996.tb00425.x

Larson, M. J., Kaufman, D. A. S., \& Perlstein, W. M. (2009). Neural time course of conflict adaptation effects on the Stroop task. Neuropsychologia, 47, 663-670. doi:10.1016/ j.neuropsychologia.2008.11.013

Liotti, M., Woldorff, M. G., Perez, R., III, \& Mayberg, H. S. (2000). An ERP study of the temporal course of the Stroop color-word interference effect. Neuropsychologia, 38, 701-711. doi:10.1016/S00283932(99)00106-2

Markela-Lerenc, J., Ille, N., Kaiser, S., Fiedler, P., Mundt, C., \& Weisbrod, M. (2004). Prefrontal-cingulate activation during executive control: Which comes first? Cognitive Brain Research, 18, 278-287. doi:10.1016/j.cogbrainres.2003.10.013

Meier, B., \& Rey-Mermet, A. (2012a). Beyond feature binding: Interference from episodic context binding creates the bivalency effect in task-switching. Frontiers in Psychology, 3, 386-394. doi:10.3389/ fpsyg.2012.00386

Meier, B., \& Rey-Mermet, A. (2012b). Beyond monitoring: After-effects of responding to prospective memory targets. Consciousness and Cognition, 21, 1644-1653. doi:10.1016/j.concog.2012.09.003
Meier, B., Rey-Mermet, A., Woodward, T. S., Müri, R., \& Gutbrod, K. (2013). Episodic context binding in task switching: Evidence from amnesia. Neuropsychologia. doi:10.1016/j.neuropsychologia.2013.01.025

Meier, B., Woodward, T. S., Rey-Mermet, A., \& Graf, P. (2009). The bivalency effect in task switching: General and enduring. Canadian Journal of Experimental Psychology, 63, 201-210. doi: $10.1037 / \mathrm{a} 0014311$

Meiran, N. (2008). The dual implication of dual affordance: Stimulustask binding and attentional focus of changing during task preparation. Experimental Psychology, 55, 251-259. doi:10.1027/ 1618-3169.55.4.251

Meiran, N., Kessler, Y., \& Adi-Japha, E. (2008). Control by action representation and input selection (CARIS): A theoretical framework for task switching. Psychological Research, 72, 473-500. doi:10.1007/s00426-008-0136-8

Notebaert, W., Houtman, F., Van Opstal, F., Gevers, W., Fias, W., \& Verguts, T. (2009). Post-error slowing: An orienting account. Cognition, 111, 275-279. doi:10.1016/j.cognition.2009.02.002

Notebaert, W., \& Verguts, T. (2011). Conflict and error adaptation in the Simon task. Acta Psychologica, 136, 212-216. doi:10.1016/ j.actpsy.2010.05.006

Nùñez Castellar, E., Kühn, S., Fias, W., \& Notebaert, W. (2010). Outcome expectancy and not accuracy determines post-error slowing: ERP support. Cognitive, Affective, \& Behavioral Neuroscience, 10, 270-278. doi:10.3758/CABN.10.2.270

Rey-Mermet, A., \& Meier, B. (2012a). The bivalency effect: Adjustment of cognitive control without response set priming. Psychological Research, 76, 50-59. doi:10.1007/s00426-011-0322-y

Rey-Mermet, A., \& Meier, B. (2012b). The bivalency effect: Evidence for flexible adjustment of cognitive control. Journal of Experimental Psychology: Human Performance and Perception, 38, 213-221. doi:10.1037/a0026024

Rogers, R. D., \& Monsell, S. (1995). Costs of a predictable switch between simple cognitive tasks. Journal of Experimental Psychology. General, 124, 207-231. doi:10.1037//0096-3445.124.2.207

Smith, R. E. (2003). The cost of remembering to remember in eventbased prospective memory: Investigating the capacity demands of delayed intention performance. Journal of Experimental Psychology: Learning, Memory, and Cognition, 29, 347-361. doi:10.1037/0278-7393.29.3.347

Spapé, M. M., Band, G. P. H., \& Hommel, B. (2011). Compatibilitysequence effects in the Simon task reflect episodic retrieval but not conflict adaptation: Evidence from LRP and N2. Biological Psychology, 88, 116-123. doi:10.1016/j.biopsycho.2011.07.001

Steinhauser, M., \& Hübner, R. (2009). Distinguishing response conflict and task conflict in the Stroop task: Evidence from Ex-Gaussian distribution analysis. Journal of Experimental Psychology. Human Perception and Performance, 35, 1398-1412. doi:10.1037/ a0016467

Strik, W. K., Fallgatter, A. J., Brandeis, D., \& Pascual-Marqui, R. D. (1998). Three-dimensional tomography of event-related potentials during response inhibition: Evidence for phasic frontal lobe activation. Electroencephalographie and Clinical Neurophysiology, 108, 406-413. doi:10.1016/S0168-5597(98)00021-5

Ullsperger, M., Bylsma, L. M., \& Botvinick, M. M. (2005). The conflict adaption effect: It's not just priming. Cognitive, Affective, \& Behavioral Neuroscience, 5, 467-472. doi:10.3758/CABN.5.4.467

Vandierendonck, A., Liefooghe, B., \& Verbruggen, F. (2010). Task switching: Interplay of reconfiguration and interference control. Psychological Bulletin, 136, 601-626. doi:10.1037/a0019791

van Veen, V., \& Carter, C. S. (2002). The anterior cingulate as a conflict monitor: fMRI and ERP studies. Physiology \& Behavior, 77, 477-482. doi:10.1006/nimg.2001.0923

Waszak, F., Hommel, B., \& Allport, A. (2003). Task-switching and long-term priming: Role of episodic stimulus-task bindings in 
task-shift costs. Cognitive Psychology, 46, 361-413. doi:10.1016/ S0010-0285(02)00520-0

West, R. (2003). Neural correlates of cognitive control and conflict detection in the Stroop and digit-location tasks. Neuropsychologia, 41, 1122-1135. doi:10.1016/S0028-3932(02)00297-X

West, R., Bowry, R., \& McConville, C. (2004). Sensitivity of medial frontal cortex to response and nonresponse conflict. Psychophysiology, 41, 739-748. doi:10.1111/j.14698986.2004.00205.x

West, R., Jakubek, K., Wymbs, N., Perry, M., \& Moore, K. (2005). Neural correlates of conflict processing. Experimental Brain Research, 167, 38-48. doi:10.1007/s00221-005-2366-y

Wirth, M., Horn, H., Koenig, T., Razafimandimby, A., Stein, M., Müller, T., et al. (2008). The early context effect reflects activity in the temporo-prefrontal semantic system: Evidence from electrical neuroimaging of abstract and concrete word reading. NeuroImage, 42, 423-436. doi:10.1016/j.neuroimage.2008.03.045

Woodward, T. S., Meier, B., Tipper, C., \& Graf, P. (2003). Bivalency is costly: Bivalent stimuli elicit cautious responding. Experimental Psychology, 50, 233-238. doi:10.1027//1618-3169.50.4.233

Woodward, T. S., Metzak, P. D., Meier, B., \& Holroyd, C. B. (2008). Anterior cingulate cortex signals the requirement to break inertia when switching tasks: A study of the bivalency effect. NeuroImage, 40, 1311-1318. doi:10.1016/j.neuroimage.2007.12.049

Wylie, G., \& Allport, A. (2000). Task switching and the measurement of "switch costs". Psychological Research, 63, 212-233. doi:10.1007/s004269900003

Wylie, G. R., Javitt, D. C., \& Foxe, J. J. (2003). Task switching: A high-density electrical mapping study. Neurolmage, 20, 23222342. doi:10.1016/j.neuroimage.2003.08.010 